\title{
Lazer e utopia: limites e possibilidades de ação política
}

Fernando Mascarenhas*

Resumo: Este texto apresenta uma síntese propositiva na direção do revigoramento das políticas de lazer. Ancorado numa concepção dialética da história, funda-se no balanço crítico das mudanças que imputaram ao lazer, ao longo das duas últimas décadas, a marca da mercadoria, bem como no exame das contradições inerentes a este processo em suas possibilidades superadoras. Sustenta propostas concretas, fixando apontamentos programáticos para uma política pública de lazer, além de reivindicar uma estratégia pedagógica que, na ação cotidiana de tais políticas, possa potencializar, junto à sociedade civil, um outro tipo de sociabilidade e experiência lúdica, articulada à utopia de um novo modo de se conceber $\mathrm{e}$ organizar a vida.

Palavras-chave: lazer, educação, políticas sociais.

Antes de tudo, cabe registrar que os limites e possibilidades de ação política aqui apontados foram consubstanciados como resultado de uma ampla análise investigativa que nos permitiu compreender e explicar a lógica venal que vem estimulando a proliferação de novas práticas de divertimento entre significativa parcela da população brasileira, conferindo formato a uma dinâmica social em que o lazer, anteriormente vinculado às necessidades de produção e reprodução da força de trabalho, como uma espécie de antivalor, passa a subordinar-se diretamente a produção e reprodução do capital, sucumbindo, de modo tendencial e dominante, à forma mercadoria. ${ }^{1}$ Não se tratam de proposições desconexas, tampouco derivam de uma capitulação reformista. Ao mesmo tempo em que se assentam sobre princípios ético-políticos e num projeto histórico de sociedade, desdobram-se numa perspectiva de transição, tentando fugir tanto ao voluntarismo típico das leituras crítico-idealistas, que ignoram as tensões e os interesses objetivos que perpassam o lazer no presente, como das interpretações de viés crítico-repro-

1 Referimo-nos à pesquisa que realizamos, em nível de doutoramento, junto ao Programa de Pós-Graduacão em Educação Física da Unicamp, sob orientação do Programa de Pós-Graduação em Educação Física da Unicamp, sob orientação do
Prof. Dr. Lino Castellani Filho, cujo resultado está sistematizado na tese "Entre o orof. Dr. Lino Castellani Filho, cujo resultado está sistematizado na tese "Entre o ponível em: http://boletimef.org/.

Movimento, Porto Alegre, v. 11, n. 3, p. 155-182, setembro/dezembro de 2005 
dutivista, afirmando-o como tempo e espaço homogêneo de reprodução e legitimação do modo de produção capitalista.

Trata-se, portanto, de uma síntese propositiva que vislumbra o revigoramento das políticas sociais, especialmente, das políticas de lazer, hodiernamente, em decorrência da desintegração do Estado de Bem Estar, transmutadas em serviços sociais competitivos. Ancorada numa concepção dialética da história, funda-se no balanço crítico das mudanças econômicas, políticas e culturais que imputaram ao lazer, ao longo das duas últimas décadas, a marca da mercadoria, bem como no exame das contradições inerentes a este processo e em suas possibilidades superadoras. O intento é o de mapear as bifurcações que se colocam e que se abrem para a construção de alternativas, procurando identificar, no jogo das forças sociais em disputa, aquilo que pode se viabilizar no sentido da conquista da cidadania participativa. Queremos com isso discutir os princípios e o norte necessário para a ação política de quem almeja e compartilha a vontade coletiva de fazer realidade um "outro lazer", crítico e superador em relação a sua mercantilização atual. Isto para poder apresentar propostas concretas, fixando apontamentos mais críveis que possam compor a base programática de uma política pública de lazer, além de reivindicar uma pedagogia crítica do lazer que, no desenrolar cotidiano de tais políticas, possa potencializar, junto à sociedade civil, especialmente, aos setores populares, um outro tipo de sociabilidade e experiência lúdica, articulada à utopia de um novo modo de se conceber e organizar a vida.

\section{Outro lazer é possível}

O primeiro e grande enigma que se abre para aqueles que direta ou indiretamente estão envolvidos com o lazer, particularmente para os que estão empenhados em qualificar a condição da existência humana, é saber se existem alternativas à mercantilização. Pois à medida que as pessoas introjetam o valor e as relações mercantis como princípio orientador de interpretação e organização da vida, igual dinâmica faz com que elas aceitem o "mercolazer" como paradigma exclusivo para a interpretação e organização do lazer. Na

2 A expressão categorial "mercolazer" procura traduzir tanto a dinâmica tendencial de mercantilização do lazer em sua manifestação mais imediata, quando assume a forma de uma mercadoria propriamente dita, como, também, sua manifestação como: valor de uso prometido, quando seu poder imagético, como coisa significante, aparece involucralmente colado ao corpo de outras mercadorias; como

Movimento, Porto Alegre, v. 11, n. 3, p. 155-182, setembro/dezembro de 2005 
esfera mais objetiva, basta a pergunta sobre um serviço de lazer pelo qual não seja preciso pagar pelo acesso para termos uma dimensão do quão corrompida anda sua experiência. Óbvio que certas modalidades tradicionais de lazer, ainda refratárias às relações mercantis, podem ser localizadas. Mas a dificuldade de identificarmos com certa prontidão e segurança alguma prática de lazer que não tenha sucumbido à forma mercadoria, por si só, já constitui obstáculo para a construção de alternativas.

Ao tempo em que o mercado se torna o lugar comum das práticas de lazer e ao tempo também em que a indústria cultural globalizada - particularmente, a grande indústria do lazer - se encarrega de dizer qual é o bom e o melhor lazer, fica parecendo que nada mais é possível fora do "mercolazer", que não há alternativas que valham a pena considerar. Diante da reconversão das formas ideológicas pelas quais atualmente se entabula a noção de lazer qualquer projeto que se vislumbre de um "outro lazer" soa como utópico. E se entendemos a utopia não no sentido de algo irrealizável, mas de objetivos que sintetizam uma vontade coletiva cuja realização não se pode precisar no tempo, sim, podemos dizer que tal projeto é realmente utópico. Isto porque assumir o projeto de um "outro lazer" significa também assumir o projeto histórico de uma "outra sociedade". Ou seja, uma sociedade que garanta a todos os seus membros o efetivo direito de acesso aos bens e riquezas materiais e simbólicas produzidas, assegurando-lhes democraticamente a condição de cidadania, dispensando-lhes igual tratamento sob o ponto de vista da condição comum de cidadãos, livres das relações de dominação, opressão, exploração ou exclusão.

Nesta direção, tanto a alternativa de um "outro lazer" como a alternativa de uma "outra sociedade" devem ser entendidas como um só projeto mobilizador que, embora não possa ser precisado no tempo, é um projeto que congrega aspirações e sintetiza uma certa intencionalidade comum, nossa própria noção de utopia. O projeto de um "outro lazer" está, de tal modo, em sintonia com a noção de história aberta, apontando para uma possibilidade de futuro, todavia, como possibilidade em movimento, imediatamente dialetizada às contradições, tensões e tendências do presente, sem esquecer ainda das determinações que lhe são impostas como herança do passado. Além de um projeto mobilizador que formula um pensa-

palco de vivências, servindo de atrativo divertido e emprestando o estatuto do lazer a um conjunto de pontos de venda ou equipamentos de comércio; e como compra divertida, quando o próprio processo de troca assume a identidade de uma atividade de lazer. Ver Mascarenhas (2005).

Movimento, Porto Alegre, v. 11, n. 3, p. 155-182, setembro/dezembro de 2005 
mento teórico, alimenta uma nova ética, organiza resistências e propõe medidas de ação concretas para curto e médio prazo, o projeto de um "outro lazer" deve se constituir como uma alternativa dinâmica e de longa empreita, sobrevivendo no tempo à custa da autocrítica, reatualizando-se constantemente.

\begin{abstract}
A perspectiva de longo prazo é necessária porque a meta real da transformação só pode estabelecer-se dentro de tal horizonte. Ademais, sem identificar a meta adequada, seguramente seria como viajar sem bússola e, portanto, as pessoas envolvidas poderiam desviar-se facilmente de seus objetivos vitais. Por outro lado, a compreensão das determinações objetivas e subjetivas do "aqui e agora" é igualmente importante. Pois a tarefa de instituir as mudanças necessárias se define já no presente, no sentido de que ao menos comece a realizar-se no "exatamente aqui e agora" ou não chegaremos à parte alguma (MÉSZÁROS, 2003, p. 122).
\end{abstract}

Assumir projetos e enxergar alternativas não significa, desta forma, traçar planos para a eternidade. É assim que nossa utopia, sobre a base de objetivos efetivamente possíveis, expressa o projeto de uma sociedade cuja estrutura e organização são qualificadoras da condição de existência dos homens. No entanto, não abrimos mão de certos princípios, a bússola encravada no "aqui e agora" que nos orienta diante da infinidade de bifurcações apresentadas pela dinâmica do presente. Se hoje vivemos sob o império da economia de mercado, na qual predomina a espontaneidade, a desregulação e a escolha individual, o horizonte da transformação reclama uma economia de planificação abrangente, centrada no desenvolvimento humano. Pois se na economia de mercado a produção orienta-se para o lucro e o consumo para o ter mais coisas, com a planificação, busca-se uma produção voltada para a necessidade e um consumo orientado para o ser mais humano.

Assim, ao colocar em perspectiva uma "outra sociedade", a "sociedade para além do capital", da qual fala Mészáros (2002), para além de experiências temporais subordinadas à lógica do sobretrabalho - isto é, do tempo necessário à extração de excedentes -, postulamos a potencialidade positiva do tempo das pessoas, desde já, lutando pela conquista de um tempo livre de trabalho para a prática da liberdade e exercício da cidadania, contrário ao tempo livre atualmente formatado, alienado e servil ao trabalho obrigatório e às relações mercantis. Isto quer dizer que antever o porvir de uma nova economia do tempo significa enfatizar a perspectiva de longo prazo, mas sem desprezar o "aqui e agora" da estrutura e do tipo de sociabilidade que se processa no tempo livre atual. Nesse sentido, um tempo livre para o exercício de ser livre é também um resultado imediato, uma possibilidade que se desenha no contem-

Movimento, Porto Alegre, v. 11, n. 3, p. 155-182, setembro/dezembro de 2005 
porâneo das contradições atuais, a transição que se define já no presente enquanto pensamento estratégico de luta e decisão.

Por conseguinte, o projeto de um "outro lazer" não deve ser visto como uma conquista inexorável, como o desenho de uma história progressiva e linear em direção ao "reino da liberdade". Apenas prefigura um porvir que não tem nada a ver com a certeza de um fim absolutamente previsível. E aí, é importante saber que alternativas não podem surgir senão pela intencional deslegitimação da situação existente, chamando sempre atenção para a incapacidade da economia capitalista de assegurar as bases materiais para o bem estar de todos os seres humanos. No tocante ao lazer, é preciso começar pela destruição da idéia de que não existem alternativas ao "mercolazer", a iniciar pela denúncia de sua natureza polarizadora. A perspectiva de um "outro lazer" se apresenta, de tal modo, como uma utopia absolutamente plausível, desde que compreendida como um projeto, ao mesmo tempo, tão perto e tão longe, um projeto de grande fôlego, dialetizado à construção de um outro projeto societário, mas um projeto que já se constrói no "aqui e agora", em nosso terreno específico de ação política e pedagógica, com a "lazerania" que vamos conquistando.

E o que estamos concebendo como "lazerania", ao passo em que procura expressar a possibilidade de apropriação do lazer como um tempo e espaço para a prática da liberdade, para o exercício da cidadania, busca traduzir a qualidade social de uma sociedade cujo direito ao lazer pode ter seu reconhecimento alicerçado sobre princípios como planificação, participação, autonomia, organização, justiça e democracia, deixando de ser monopólio ou instrumento daqueles que concentram poder econômico (MASCARENHAS, 2004). Nesse sentido, a conquista da "lazerania" pressupõe um projeto de formação. É a educação informal, alegre e lúdica ${ }^{3}$ que, podendo se manifestar pelas mais diferentes práticas, nos mais diversos ambientes, como tempo e espaço de organização da cultura, faz-se instrumento político e pedagógico de transformação social. Distante da

3 Não podemos esquecer do caráter lúdico e espírito de alegria que deve estar na base de qualquer proposta de lazer. O lazer, indiscutivelmente, tem de ser motivo de alegria, tal qual a concebe Snyders (1988), não como prazer imediato - algo que é próprio do "mercolazer"-, mas como a alegria provocada e estimulada pela satisfação de acesso e apropriação da cultura elaborada. Dentro de um ambiente lúdico, as atividades de lazer constituem uma prática educativa das mais privilegiadas para fruição e exercício dos sentidos e das emoções, deste modo, bastante propícia à alegria da criação, do triunfo, do conhecimento, do prazer estético e da qualidade.

Movimento, Porto Alegre, v. 11, n. 3, p. 155-182, setembro/dezembro de 2005 
noção que restringe o lazer ao prazer e gozo individual de objetos de fruição disponibilizados no mercado, a "lazerania" requer participação, pois objetiva o exercício do poder a partir da sociedade civil organizada, ${ }^{4}$ articulando-se à capacidade dos "de baixo" - isto é, dos setores populares - de se impor e de se autodeterminar.

A "lazerania" tem como objeto central de preocupação a educação, sempre buscando proporcionar meios e condições aos sujeitos que de seu exercício tomam parte para refletirem sobre suas condições de vida e sobre a sociedade mais ampla na qual estão inseridos, possibilitando-lhes não só o acesso, mas o entendimento do lazer como manifestação de uma cultura e como possível instrumento de ligação com sua realidade. Tem seus propósitos fincados sobre a noção de sujeito social, afastando-se da passividade que cerca a atual condição de consumidor comum à experiência do "mercolazer". E mais, preconiza a noção de direitos e deveres, incentivando a participação para a tomada de decisões que correspondem à organização de uma dada coletividade, procurando garantir a reflexão acerca das relações de poder e do significado das regras e valores necessários à convivência comum, desmistificando o subjetivismo axiológico que cerca a idéia de lazer como fazer o que se quer, entendendo a liberdade, que deve ser inerente à sua prática, como consciência da necessidade.

A conquista da "lazerania" não é, assim, tarefa para uma única pessoa. É um desafio que precisa envolver os diferentes atores e forças socialmente comprometidas que interagem direta e indiretamente com o lazer. Temos então diante de nós a exigência de um diálogo impensável para aqueles que crêem na rápida tomada do poder como estratégia de transformação social. Temos pela frente um grande esforço teórico a ser construído, tarefa que deve reunir pensadores e lideranças de variadas tendências progressistas. No campo do lazer, a despeito das contradições internas, tal articulação deve se efetivar. Isto, pois somente a um intelectual-coletivo é possível o papel de organização de uma nova função para o lazer, uma funcionalidade desinteressada do ponto de vista prático-material,

4 Advertimos aqui para o metamorfoamento do conceito de sociedade civil, cujo emprego, como aponta Nogueira (2003), cada vez mais tem reduzido seu significado a um acampamento de movimentos fragmentários onde até se percebe o crescimento de organização dos interesses e de mobilização democrática, mas que, mais e mais, de organização dos interesses e de mobilização democrática, mas que, mais e mais, dade de articulação política dos interesses populares, ou seja, seu sentido rigorosamente gramsciano de terreno para a afirmação de projetos de hegemonia, o qual devemos reafirmar.

Movimento, Porto Alegre, v. 11, n. 3, p. 155-182, setembro/dezembro de 2005 
mas uma funcionalidade interessada no que se refere ao projeto de emancipação humana, uma função portadora da qualidade social que postula a reinvenção do lazer como um tempo e espaço no e pelo qual os homens poderão por em exercício lúdico toda sua potencialidade crítica, criadora e, acima de tudo, sócio-transformadora.

\section{Política de lazerania}

Aqui se impõe a tarefa de nos determos sobre a relação que guardam entre si a estrutura econômica e a superestrutura política e ideológica historicamente determinada. Isto, pois a organização política, não obstante às estruturas dadas, joga peso fundamental na possibilidade de reveses na lógica de desenvolvimento do capitalismo. Afastamo-nos, de tal modo, da interpretação que concebe a superestrutura como espelho da estrutura. Esse tipo de leitura, economicista, como adverte Portelli (1990), pode facilmente nos conduzir à passividade política, protegidos pela crença de que a evolução natural da estrutura nos levará inexoravelmente à transformação da superestrutura, tratada então como seu puro reflexo. Não se pode negar que a estrutura, de algum modo, determina a superestrutura. Mas o contrário também é verdade. Estrutura e superestrutura - talvez fosse melhor dizer estrutura-superestrutura ${ }^{5}$ - determinam-se mutuamente, constituindo momentos distintos da vida social, porém, orgânicos à mesma totalidade histórica.

Em sendo assim, a organização política e cultural que se desenvolve no plano da superestrutura pode muito bem se materializar como práxis na e pela qual os homens se conscientizem e se posicionam ante as tensões que se desenvolvem no plano da estrutura. É justamente aí que se revela a dimensão estrutural da organização política e cultural, cuja centralidade está no trabalho, protoforma do universo da práxis social. Seria idealismo atribuir o movimento da história apenas à consciência e à ação política, independente das bases econômicas e materiais que se impõem à organização da vida. Por outro lado, se admitimos que a superestrutura não é simples reflexo das condições estruturais, a possibilidade da ação política entra em cena podendo contribuir

5 Há de se reconhecer o peso das condições estruturais, mas sempre numa relação de unidade de contrários, no qual os dois pólos ao mesmo tempo em que se necessitam, também se contraditam, por vezes, um se sobrepondo ao outro, todavia, algo que acontece apenas em caráter transitório, de acordo com o momento histórico específico.

Movimento, Porto Alegre, v. 11, n. 3, p. 155-182, setembro/dezembro de 2005 
tanto para a naturalização das desigualdades como para a conquista da autodeterminação popular, para a radicalização da democracia e para o esforço planejado de transformação social, reconhecendo as condições objetivas impostas, mas tomando-as, ao mesmo tempo, como ponto de partida histórico para a construção de uma nova sociedade.

O agir revolucionário não é o imperativo de uma capacidade adestrada para fazer a história, mas o engajamento num conflito de resultado incerto. [...] Para cada época, o presente histórico representa o coroamento de uma história consumada e a força inaugural de uma aventura que (re)começa. Trata-se de um presente propriamente político, estrategicamente identificado com a noção de circunstâncias "encontradas, dadas, transmitidas" nas quais "os homens fazem sua própria história". A política é o modo desse fazer. [...] Politizada, a história torna-se inteligível a quem quer agir para mudar o mundo. "A política passa doravante à frente da história" (BENSAID, 1999, p. 109-133).

Para que mudanças sociais mais significativas aconteçam, no entanto, são necessárias condições objetivas e subjetivas favoráveis, sobressaindo uma ou outra, a depender da realidade contextual e do momento histórico. Nesta perspectiva, nos limites de um país cuja sociedade civil já se encontra fortalecida ou em vias de fortalecimento - como julgamos ser o caso do Brasil a partir da redemocratização -,${ }^{6}$ a "guerra de posições", de acordo com Gramsci (1976), traduz a melhor estratégia que a organização e a luta dos setores populares pode e deve assumir, disputando a sociedade política e reclamando a condução das políticas sociais, tomando-as como um poderoso instrumento e força mobilizadora da transformação. Fazer das políticas sociais um espaço de participação significa, deste modo, colocar em evidência a dimensão das condições subjetivas, conferindo importância à ação política de sujeitos coletivos que, mesmo dentro de uma estrutura social dada, podem jogar um peso importante na conquista de posições em reforço à luta hegemônica pelo estabelecimento de novos parâmetros para a organização das relações de poder e da vida comum.

6 Conforme destaca Amaral (2004, p. 4), na década de 1980, depois de um longo período ditatorial, quando tem início o processo de redemocratização, "o cenário nacional concedeu espaço para duas conquistas em relação à participação: cons-
tituiu-se um campo democrático no interior da sociedade civil formado, sobretutituiu-se um campo democratico no interior da sociedade civil formado, sobretu-
do, pelos movimentos populares e pelos movimentos sociais pluriclassistas, do, pelos movimentos populares e pelos movimentos sociais pluriclassistas,
que desenvolveu uma cultura política de mobilização e de pressão direta para que desenvolveu uma cultura política de mobilização e de pressão direta para cipação da população em assuntos que dizem respeito à administração pública". Também para a autora, isto teria aberto caminho para a guerra de posições em torno da possibilidade da gestão participativa das políticas públicas, incluso as políticas de lazer.

Movimento, Porto Alegre, v. 11, n. 3, p. 155-182, setembro/dezembro de 2005 
As políticas sociais podem resultar num dialético empurrão da superestrutura sobre a estrutura, contribuindo para deslegitimação ideológica da segunda. Articulada à luta mais ampla por uma parametrização socialmente referenciada para o conjunto das polí ticas públicas, a disputa hegemônica em torno das políticas de lazer revela-se, desta forma, como a estratégia mais apropriada - e, vale dizer também, necessária - para pôr em marcha a construção de alternativas ao processo de mercantilização que apanha o lazer. Tal disputa deve se traduzir, portanto, por uma articulação que busque pautar as políticas de lazer pela organização de diferentes formas de sociabilidade, forjando práticas, valores e comportamentos verdadeiramente solidários, buscando, a partir da especificidade do trabalho e da intervenção que se operam no e pelo lazer, contribuir para o desenvolvimento de uma humanidade renovada.

Mas a política social é apenas uma dimensão da política pública, cobrando, assim, uma política econômica condizente com o projeto de desenvolvimento humano que se preconiza, impondo limites à lógica mercantil que hoje comanda a "despolitização" dos Estados Nacionais. Política social requer compromisso econômico. É bom que se dê atenção a isto, pois as atuais políticas econômicas não têm nada de sociais. Ao contrário, são políticas de exclusão. Porquanto, o crescimento econômico sustentado pautado pela distribuição socialmente justa de nossas riquezas é instrumento indispensável na construção de mecanismos de resgate da dívida social do país. Na mesma direção, para que as políticas de lazer sejam capazes de promover a democratização do acesso a este que é um direito de todos cidadãos, de modo articulado, seria necessária uma reorientação política muito mais ampla, tanto no plano social como na esfera econômica, a começar pelo combate ao abuso do sobretrabalho, o que visa reduzir a participação do trabalho no tempo de vida dos brasileiros.

Estamos, com isso, elegendo a problemática do tempo livre como uma das prioridades para a "política de lazerania". Tal política reclama, assim, uma política econômica que tenha como meta o crescimento da produção combinado com a redistribuição da renda para a promoção do menor tempo de trabalho. Isto porque o aumento do tempo livre é um pressuposto para o desenvolvimento do lazer. Neste ínterim, como reivindica Antunes (1999, p. 177), “a luta pela redução da jornada ou tempo de trabalho deve estar no centro das ações no mundo do trabalho hoje, em escala mundial", pois a contenção do sobretrabalho, no plano mais imediato, tem o potencial de minimizar o desemprego estrutural. Há de se advertir,

Movimento, Porto Alegre, v. 11, n. 3, p. 155-182, setembro/dezembro de 2005 
no entanto, que a diminuição do tempo de trabalho não pode resultar em rebaixamento de salário, como normalmente acontece. À redução da jornada deve ser somada a ampliação do rendimento da população trabalhadora. ${ }^{7}$

Com salários maiores, o estímulo ao abuso do sobretrabalho decresce [...]. A luta pelo tempo livre deve vir acompanhada da melhor distribuição de renda, por meio da elevação dos rendimentos do trabalho, da modificação do sistema tributário e de transferência de renda. Quanto mais se valorizar o rendimento do trabalho, maiores são as possibilidades de o homem transitar da atividade laboral para a inatividade, em busca do tempo livre (POCHMANN, 2002, p. 111-112).

Nesse sentido, a proposta da redução da jornada de trabalho, sem corte de salários, para que possa responder às efetivas necessidades presentes no cotidiano da classe trabalhadora, deve ter como base argumentativa principal, a criação de novos empregos, até porque, frente ao contexto de desemprego estrutural que assola o país, esta é uma reivindicação suficientemente capaz de mobilizar a opinião pública a seu favor. Mas deve ainda incluir o combate ao preconceito contra a inatividade, pautando-se também pela necessidade de universalização do direito ao tempo livre entre os trabalhadores. Como defende a CUT, a luta do trabalho para todos passa pela idéia de se trabalhar menos para que todos trabalhem. No entanto, é preciso dizer, ao mesmo tempo, que a luta pela redução da jornada não é somente uma luta por mais empregos. Constitui, igualmente, uma luta por mais tempo livre para que os trabalhadores possam se dedicar à família, envolverem-se em programas educativos e de lazer, ou simplesmente, entregarem-se ao descanso e à contemplação. ${ }^{8}$

Porém, essa luta pelo direito ao trabalho em tempo reduzido e pela ampliação do tempo fora do trabalho (o chamado "tempo livre"), sem redução de salário - o que, faça-se um parênteses, é muito diferente de flexibilizar a jor-

7 Neste ponto, as duas maiores centrais sindicais brasileiras, CUT e Força Sindical, apresentam proposições diferentes para a redução da jornada. A CUT propõe redução da jornada de trabalho de 44 para 40 horas, sem redução de salário. Já a Força Sindical, defende a redução da jornada de 44 para 36 horas, mediante acordo entre trabalhadores, empresários e governo, com a redução de salários, lucro e impostos. Para saber mais, ver Mascarenhas (2002).

8 Vale lembrar que a ampliação do tempo livre, para além da redução da jornada que incide diretamente sobre o tempo livre do final do dia -, demanda também políticas trabalhistas que assegurem o descanso semanal remunerado e as férias ou seja, o tempo livre do final de semana e o tempo livre do final de ano-, direitos que, no contexto das políticas neoliberais, vêm sendo duramente atacados. Isto sem falar de uma política previdenciária que assegure aposentadoria digna ao conjunto dos brasileiros, o que possibilitaria aos idosos o bom aproveitamento do tempo livre do final da vida.

Movimento, Porto Alegre, v. 11, n. 3, p. 155-182, setembro/dezembro de 2005 
nada, uma vez que esta se encontra em sintonia com a lógica do capital deve estar intimamente articulada à luta contra o sistema de metabolismo social do capital que converte o "tempo livre" em tempo de consumo para o capital, onde o indivíduo é impelido a "capacitar-se" para melhor "competir" no mercado de trabalho, ou ainda a exaurir-se num consumo coisificado e fetichizado, inteiramente desprovido de sentido (ANTUNES, 1999, p. 178).

A disciplina do trabalho instituída pela razão instrumental e o processo de mercantilização da vida constituem empecilhos para que a pauta do direito ao tempo livre e ao lazer seja colocada em alto e bom som ao lado da luta pela redução da jornada. Se de um lado a inatividade continua sendo associada à preguiça e à vadiagem, de outro, o lazer, majoritariamente subordinado à lógica do consumo, muitas vezes, acaba por ser considerado um luxo. Assumidos subjetivamente desta forma, tempo livre e lazer continuam, assim, fora da pauta mais imediata de reivindicações dos trabalhadores. Diante disso, como forma de contrapor à pressão pelo trabalho e à venalidade generalizada no terreno da fruição e dos divertimentos, a intervenção pública é fundamental, forjando parte das condições necessárias para uma outra mentalidade, com aumento dos programas e espaços públicos voltados para o lazer.

As praças públicas, os centros de recreação e de cultura popular, entre tantas outras atividades [possíveis] de fortalecimento do uso emancipatório do tempo livre, constituem alguns exemplos de que a inatividade somente pode ser aprofundada se houver o que fazer fora do trabalho tradicional, principalmente fundado na existência de mecanismos de financiamento do tempo livre. De outra forma, lamentavelmente, deverá ser cada vez mais o shopping center o local privilegiado do exercício do ócio não-criativo, praticado apenas pelos que têm dinheiro (POCHMANN, 2002, p. 112-113).

O problema consiste, então, em ampliar o tempo livre e os rendimentos da população trabalhadora sem, no entanto, contribuir para reafirmar a mercantilização da vida através do estímulo ao consumo do "mercolazer". Mas se a contradição que se apresenta é a do público versus o privado, nada mais desafiador do que sustentar uma política que tenha a compreensão do lazer como um direito social básico de todos, o que requer a ampliação do fundo público no sentido da "repolitização" do Estado no tocante à sua responsabilidade social quanto ao custeio desta mesma política. No entanto, isso esbarra na recuperação da capacidade estatal para conduzir políticas sociais alternativas. Por enquanto, os investimentos do setor privado são de longe maiores que aqueles realizados pelo setor público, cabendo, ao segundo, o financiamento do primeiro.

Movimento, Porto Alegre, v. 11, n. 3, p. 155-182, setembro/dezembro de 2005 
Há, assim, a necessidade de se por freios ao crescimento desordenado da grande indústria do lazer, com medidas que envolvem desde a possibilidade de taxação sobre os lucros do setor, a fim de impor limites à concentração do "capital divertido", até o retorno gradual dos impostos sobre a transferência de lucros e importação de máquinas e equipamentos de lazer, hoje, algo desonerado, o que constituiria um duro golpe na dinâmica monopolista do "mercolazer". Mas seria preciso ainda, redirecionar o financiamento público destinado aos negócios do lazer. Ao invés de patrocinar o desenvolvimento concêntrico do "mercolazer" - como, por exemplo, na concessão de empréstimos pelo BNDES para a construção de shoppings, parques temáticos ou mega-empreendimentos turísticos -, o fundo estatal deveria investir na ampliação do acesso ao microcrédito para cooperativas e política de subsídios para as pequenas empresas de lazer com atividades efetivamente orientadas para a promoção da cultura lúdica, do bem-estar humano, da dignidade das pessoas e do respeito à natureza.

Uma "política de lazerania" deve estar articulada ainda a uma política de cidades. Isto, pois é cada vez mais evidente a reconfiguração imposta à geografia de nossas urbes pela dinâmica expansiva do "mercolazer". Como as formas de apropriação da cidade expressam o modo das relações de produção, desenvolvimento desigual, concentração, exclusão etc., tudo isso está presente também no modo de vida urbano. Nesse sentido, é o poder do dinheiro e da especulação que traça o desenho das cidades. E aí, o "capital divertido" se faz emblemático. Com seus shoppings, parques, restaurantes, paisagens mercantilizadas, clubes-condomínio etc., alarga fronteiras, cria e combina fluxos, estabelece migrações, privatiza espaços públicos, delimita zonas de exclusão e flexibiliza territórios. Por isso a necessidade de políticas de planejamento urbano voltadas à questão da distribuição dos espaços e equipamentos de lazer, procurando, de um lado, acabar com o movimento especulativo em torno dos novos empreendimentos de "mercolazer" e, de outro, ampliar as possibilidades de lazer acessíveis para o conjunto da população.

Para tanto, deve-se interromper o sucateamento e a privatização dos equipamentos públicos de lazer - parques, estádios, ginásios, teatros, centros culturais etc. -, o que pode muito bem se viabilizar as custas de um fundo criado a partir da tributação dos serviços de "mercolazer", 9 com o financiamento público garantindo o seu uso

9 Sabemos que a política de fundos restringe responsabilidades do Estado, muitas vezes substituindo a alocação de percentuais efetivos de recursos constitucionais para a garantia de direitos. Pode ainda levar a uma gestão de pouca transparência, com instrumentos e mecanismos de controle público insuficientes, um desafio

Movimento, Porto Alegre, v. 11, n. 3, p. 155-182, setembro/dezembro de 2005 
em caráter aberto, gratuito e polivalente, organizado por uma "política de lazerania" atenta às riquezas do universo cultural e lúdico das diferentes regiões e locais, com gestão compartilhada com a sociedade civil organizada e engajamento pedagógico de educadores coletivos multi-profissionais em programas de lazer-educação. De outro lado, no tocante ainda à necessidade de ampliação quantitativa dos equipamentos de lazer disponíveis à população, deve também ser considerada a possibilidade de parcerias com setores não-mercantis ligados ao "lazer associativo" - clubes, entidades recreativas, agremiações culturais, etc.

O papel do associativismo na difusão do lazer, sobretudo do esporte, na história de nosso país, como se sabe, foi decisivo. O exemplo dos clubes é emblemático. Alargando a esfera de sociabilidade, ampliando as redes de convivência e definindo critérios de pertencimento, além de forjar novos modos de vida entre a população, eles constituíam uma forma de realizar a diferenciação de quem era quem entre os membros das classes e distintos grupamentos que compunham nossa sociedade. ${ }^{10}$ Alguns se popularizaram através do futebol e passaram a reunir legiões de torcedores. A paixão pelos times de futebol no Brasil acabou por se tornar um elemento constitutivo da identidade nacional, em maior ou menor escala, fazendo com que determinados clubes fossem incorporados ao patrimônio cultural do país. Essa história nos deixou não só uma herança repleta de simbologia e tradição em torno dos clubes, mas também uma vasta estrutura física de equipamentos cuja capilaridade e potencial aglutinador não devem ser menosprezados.

Afora os clubes, vale ainda falar das entidades recreativas de classe que, sob o ideário da política econômica do regime militar com o propósito de amenizar os conflitos entre capital e trabalho, minar a representatividade e desviar a capacidade de mobilização

a ser enfrentado pelos setores sociais organizados. Entretanto, diferentemente da educação, para citar um exemplo, cujo financiamento é assegurado através de vinculação orçamentária, os gastos com lazer encontram-se pulverizados pelos mais diferentes ç (n) país de aportes governamentais diretos em ações nesta área, normalmente estimuladas através de subvenções - como é o caso do SESI e do SESC - e de políticas de renúncia fiscal - como é o caso dos clubes e entidades recreativas de classe justificaria, como medida de curto prazo, a criação de um fundo específico a fim de ampliar o acesso da população ao lazer.

10 Para saber mais sobre a invenção, utilização e propagação do esporte e do lazer como critérios, ao mesmo tempo, de identificação e diferenciação social, ver Hobsbawm (1992).

Movimento, Porto Alegre, v. 11, n. 3, p. 155-182, setembro/dezembro de 2005 
do movimento sindical, receberam demasiado impulso por parte do governo federal durante os anos de $1970 .^{11}$ De igual modo, apesar da instrumentalização do lazer no sentido moralista, utilitário e compensatório, o saldo que tal ação deixou para o país no que se refere à capacidade instalada para as práticas de lazer é inegável. Isto sem mencionar, como bem percebe Sant'Anna (1994), o potencial que tais equipamentos de lazer, de outro lado, possuem para sediar programas sócio-educativos como estratégia de atração e organização política dos trabalhadores. Ocorre que tanto os clubes como as entidades e associações recreativas de classe, hoje não mais contando com os incentivos e auxílio governamental, vivem a mingua frente à luta concorrencial dada pelo avanço do "mercolazer", constituindo uma opção para o tempo livre cada vez menos prestigiada entre a população das grandes e médias cidades brasileiras, o que se traduz pela evasão de sócios, pela perda de receita e pelo sucateamento de sua estrutura.

A solução encontrada por alguns poucos clubes e associações diante de tais dificuldades tem sido a modernização conservadora diga-se, solução de mercado -, hibridizando mercantilização e associativismo, aderindo, assim, à lógica do "mercolazer", o que, de forma geral, contribui ainda mais para a sua consolidação como paradigma dos serviços de lazer disponibilizados à população. Uma "política de lazerania" deve estar atenta a esta situação, criando, se necessário, mecanismos de salvaguarda e, até mesmo, de fomento - o que pode incluir medidas de subsídio - para o "lazer associativo". Em contrapartida, tais entidades devem se colocar como parceiras desta política, participando e disponibilizando infraestrutura mais equipamentos para a implementação de programas e ações de governos. Ao mesmo tempo, deve ser exigida a adoção de mecanismos que visem garantir a transparência e a democratização da gestão, com o estabelecimento de normas para a descentralização e alternância de poder e a efetivação de práticas participativas nas tomadas de decisão, o que pode contribuir para o enfraquecimento do autoritarismo e do patrimonialismo que habitam tais instituições. ${ }^{12}$

11 O decreto $n^{\circ} 67.227$, de 21 de setembro de 1970, exemplifica a preocupação do governo. "O item II deste decreto estabelece que o governo concede empréstimos financeiros às entidades sindicais para a construção, reforma, ampliação ou aquisição de sedes, escolas, colônias de férias, campos de esportes, clubes recreativos sição de sedes, escolas, colônias de ferias, campos de esportes, clubes recreativos etc. Além disso, fornece incentivos à realização de atividades culturais, recreativas e civicas e à produção de concursos intersindicais que visem a estabelecer a emulação sadia quanto às atividades culturais, esportivas e educativas" (SANT'ANNA,
1994, p. 29).

12 Ainda que distante de uma gestão autenticamente participativa, baseado numa proposta de democracia consultiva de interação com os sócios, ancorada numa

Movimento, Porto Alegre, v. 11, n. 3, p. 155-182, setembro/dezembro de 2005 
Admitindo ainda a incapacidade estrutural por parte do setor público naquilo que diz respeito à dotação orçamentária, à estrutura física e aos recursos humanos disponíveis tanto para a universalização das oportunidades de lazer como para garantir a implementação e o funcionamento de programas de abrangência nacional, e, de outro lado, considerando que boa parte de programas e projetos sociais de lazer desenvolvidos no país encontram-se pulverizados nas ações de "lazer filantrópico" - em sua maioria, ancoradas em ofertas empobrecidas de "mercolazer", levadas a cabo pelo terceiro setor e entidades com caracterização jurídica mista, como é o caso do SESI e do SESC -, vale a iniciativa de submeter tais segmentos ao controle social público, fixando parâmetros e diretrizes para tal. Em outros termos, isto significa instituir certas referências de qualidade para a avaliação oficial de projetos e programas sociais de lazer.

Assim, a avaliação em proposição deixa de ser meramente quantitativa como aquela conduzida pelas políticas focalistas de cunho assistencialista que se preocupam apenas ou prioritariamente com o número de atendimentos realizados pelos projetos ou programas. Não se checa, de tal modo, nem se a intervenção tem atingido os próprios objetivos e metas aos quais se propôs atingir. Aliás, o projeto político-pedagógico, muitas vezes inexistente, é outro balizador para a avaliação. Isto porque as experiências socialmente referenciadas são as que reforçam a participação de todos os segmentos constitutivos da comunidade na elaboração, implementação e acompanhamento do seu projeto. Faz-se necessário romper com a prática estritamente formal e burocrática que tem norteado a avaliação das políticas de lazer. Sem descuidar da eficácia em termos distributivos, uma "política de lazerania", para ser autêntica, tem de se ocupar com o desenvolvimento de tecnologias sociais de avaliação suficientemente capazes de detectar os limites e as potencialidades que os mais diversos programas e projetos de lazer têm apresentado no sentido de atingir uma maior qualidade social no caminho da educação e da emancipação humana.

A qualidade social almejada para os programas e projetos de lazer, governamentais ou não, traduz-se, portanto, por um padrão

concepção de racionalização comunicativa, a experiência do Sistema AABB - atualmente com uma rede de 1.267 AABB's e 250.000 associados em todo o Brasil -, enquadrando-se num processo que Riede e Bramante (2003) chamaram de ação gerencial dialógica - ou gestão social -, merece atenção como uma alternativa concreta e aparentemente bem sucedida de modernização que tem parcialmente conseguido escapar às soluções de mercado e estabelecer um diferente padrão administrativo para o funcionamento dos clubes sociais recreativos.

Movimento, Porto Alegre, v. 11, n. 3, p. 155-182, setembro/dezembro de 2005 
de excelência e adequação às reais necessidades da maioria da população brasileira, tendo como princípios e valores ético-políticos fundamentais, a solidariedade, a justiça, a autonomia, a liberdade e, por conseguinte, a inclusão social. A orientação geral colocada para o que estamos chamando de política de "lazerania" consiste, nesse sentido, em converter a maior quantidade possível de espaços, equipamentos, projetos e programas de lazer em verdadeiras casamatas da vontade coletiva. Pressupõe a organização do lazer como mais um espaço de exercício para a autodeterminação popular rumo a uma nova direção política, da reforma intelectual e moral para uma nova direção cultural, com indivíduos e coletividades protagonizando a luta popular pela emancipação frente às estruturas de dominação e alienação, conquistando, dia-a-dia, uma participação cidadã que acumula experiências, saberes, habilidades, métodos, enfim, instrumentos de poder que reivindicam direitos, reconhecem determinações e reclamam transformações.

Ampliando o leque de preocupações, diante do desmedido avanço das atividades de lazer voltadas ao ecoturismo - com ênfase nos chamados esportes de aventura ou esportes na natureza -, um crescimento que está intimamente ligado às necessidades expansionistas e à criatividade destrutiva do capital, advertimos para o fato de que uma "política de lazerania" deve estar atenta também para a questão do lazer ambiental ou práticas de lazer na natureza. Uma vez que o "mercolazer" - de maneira especial, aquela modalidade representada pelos esportes de aventura e esportes na natureza -, transformou-se na grande vedete do mercado do turismo, agregando diversão e consumo ao patrimônio natural de várias cidades, torna-se urgente a criação de uma rígida legislação, com instrumentos de fiscalização condizentes, para a proteção do meio ambiente, impondo novas regras e limites ao processo de mercantilização das paisagens naturais em curso, incluso aí para instalação de equipamentos.

É necessário ainda tornar obrigatória por parte das empresas que operam no setor - sem descuidar dos empreendimentos realizados por municípios, fundações, ONGs, cooperativas, etc. - a realização de investimentos em educação ambiental, isto sem falar da igual necessidade de criação de mecanismos democráticos e participativos de controle social para o acompanhamento deste tipo de atividade. Por seu turno, frente à subordinação de diversas localidades às exigências impostas pela indústria cultural globalizada, o que ocorre não só pelos hábitos, valores, costumes e comportamentos difundidos pelos consumidores e turistas que chegam e

Movimento, Porto Alegre, v. 11, n. 3, p. 155-182, setembro/dezembro de 2005 
que passam, ${ }^{13}$ mas, também, pela estrutura de hospedagem, comércio e diversão que, além de provocar a privatização do espaço público, transfiguram por completo a economia local, medidas para a proteção da organização comunitária, das tradições e das produções culturais constituem outro cuidado imprescindível.

Outro problema que merece consideração diz respeito à precariedade das relações de trabalho em atividades de lazer. Ao lado da dificuldade de se definir quem é o trabalhador do lazer, o que constitui enorme empecilho tanto para o reconhecimento social deste trabalhador como para que ele próprio se perceba como tal, a enorme heterogeneidade inerente à base flexível dos serviços de lazer coloca grandes obstáculos para a organização destes trabalhadores em torno da luta por direitos e por proteção legal para sua atividade. Dispersos nos mais variados segmentos dos serviços de lazer muitos tradicionais, alguns bastante peculiares e outros até marginalizados -, na luta entre capital e trabalho, sindicalmente desorganizados, tais trabalhadores ficam a mercê das condições de oferta abundante de força de trabalho que pesa a favor dos empresários. A fim de se reverter o quadro de reduzido nível salarial, de péssimas condições de trabalho e de baixo padrão de vida que apanha a maior parte destes trabalhadores, o combate à informalidade deve ser prioridade, o que pode se efetivar com políticas de trabalho específicas, que não devem ser confundidas com as do segmento organizado de trabalho. Isto não significa fazer a opção pela flexibilização trabalhista, no oposto, visa criar condições e fixar metas para a progressiva extensão da regulamentação social do trabalho ao conjunto dos trabalhadores de lazer.

Agora, uma dúvida que ainda fica em aberto refere-se à já conhecida dificuldade para se delimitar o campo de abrangência do lazer, o que pode causar certa indefinição na divisão e atribuição de responsabilidades para a elaboração, implementação e acompanhamento das políticas e das ações sugeridas. ${ }^{14}$ É bom que se diga que

13 Conforme denuncia Sant'Anna (2001, p. 62), "o turista não carrega apenas suas roupas e equipamentos de diversão dentro da mala. Ele porta seus valores, sua expectativas e intolerâncias. Por vezes, ele leva consigo a vontade ou o hábito de ser tratado como um rei, o que implica considerar que as populações locais estão onde estão para servi-lo. Afinal, é usual o argumento de que em férias não há dever, só direitos".

14 Tal indefinição se evidencia, conforme aponta Marcellino (1987), pela própria confusão sugerida pela denominação dos órgãos públicos responsáveis pela condução das políticas de lazer, variando de Estado para Estado e de município para município, através das secretarias ou divisões de "Esporte e Lazer", "Recreação e Lazer", "Turismo e Lazer", "Turismo, Lazer e Meio Ambiente", "Lazer, Parques e Jardins", "Cultura e Lazer", "Educação, Cultura e Lazer", etc.

$M$ ovimento, Porto Alegre, v. 11, n. 3, p. 155-182, setembro/dezembro de 2005 
na base desta indefinição está a própria transversalidade das políticas de lazer. Aliás, de setoriais, tais políticas têm muito pouco. Justamente por serem transversais, além de um conjunto de regulamentações econômicas, ecológicas, sociais, políticas e culturais, cobram uma articulação intersetorial, pois perpassam os diferentes setores da administração pública e níveis de governo. Exigem ações gerais no campo da educação, do esporte, da cultura, da saúde, do meio ambiente, do turismo etc., sempre orientadas para o desenvolvimento econômico combinado ao desenvolvimento social e humano.

Todavia, se não estabelecemos algum tipo de centralidade, pode ficar parecendo que o lazer está em todos os lugares e, ao mesmo tempo, não está em lugar nenhum. Isto quer dizer que no quadro mais ampliado das atribuições dos diferentes setores de governo, o lazer deve ser pensado a partir de algum ponto de partida. Indiscutivelmente, as políticas de lazer devem ser objeto da área social, embora, como já mencionado, também mereçam atenção da área econômica. Dentro da área social, por compreendemos o lazer como uma prática essencialmente educativa, poderíamos muito bem eleger o setor da educação como locus privilegiado e centro irradiador de uma "política de lazerania". Mas vale lembrar que, em nosso país, a atribuição deste setor está, tradicional e prioritariamente, circunscrita a ações no âmbito da educação formal, inclusive do ponto de vista legal. Em sendo assim, uma vez que na experiência política brasileira é recorrente a associação do lazer à recreação e ao esporte, o que se soma à forte representação que ainda se tem deste fenômeno como uma atividade, comumente relacionado às práticas corporais, avaliamos que as políticas de lazer podem ser pensadas e potencializadas a partir do fenômeno esportivo.

É óbvio que tal estratégia não deve ser gerida pela via da "esportivização" do lazer, mas de ter no setor do esporte - talvez fosse melhor falar em setor de esporte e lazer - o centro de organização das políticas de lazer. Como componente da identidade cultural brasileira e uma das práticas sociais mais significativas da contemporaneidade, quando tratado sob a perspectiva da educação, ${ }^{15}$ conforme salienta Casttellani Filho (1998), o esporte possui

15 Tal advertência se faz necessária, pois é corrente nas várias esferas de governo a crítica ao modelo desportivo brasileiro, não obstante à todas as suas contradições, tradicionalmente partidário de uma visão que liga esportes à educação. Avaliam: "Segundo esta visão, o esporte é um sub-conjunto da formação educacional dos indivíduos e não uma atividade humana com potencial empresarial enorme. (...) Contudo, esta situação vem-se alterando e observa-se uma verdadeira revolução no esporte brasileiro, onde velhas práticas começam a ser abandonadas e novas formas

Movimento, Porto Alegre, v. 11, n. 3, p. 155-182, setembro/dezembro de 2005 
um potencial enorme para mobilizar interesses, ativar a participação, possibilitar acertos, valorizar avanços, desafiar o pensamento, melhorar a auto-estima, instalar o entusiasmo e despertar a confiança. A prática esportiva pode, de tal modo, viabilizar-se como um importante tempo e espaço de sociabilidade e de construção de uma consciência individual e coletiva representativa de uma nova relação entre corpo, conhecimento e sensibilidade, expressão de um projeto de educação multilateral.

Nesse sentido, sobram predicados e legitimidade ao setor do esporte para chamar para si o papel de agente de coordenação, articulação e difusão das políticas de lazer do país, desenvolvendo ações transversais que garantam o diálogo e a integração entre os diferentes setores - educação, cultura, saúde, meio ambiente, turismo, etc. - e esferas de governo. ${ }^{16}$ Portanto, uma "política de lazerania" estruturada a partir do fenômeno esportivo deve apontar para a organização de projetos e programas cujo tom não seja nem de formação de atletas, de treinamento desportivo, de aptidão física, ou mesmo, de recreação - tal qual já conhecemos -, mas, contemplando também estas dimensões, aliadas à arte, à música, à comunicação, à vida na natureza, ao bem estar e à qualidade de vida, à saúde, aos cuidados com o corpo etc., fazerem-se como projetos e programas para a apropriação coletiva, lúdica, crítica e criativa das diversas manifestações que compõem o patrimônio cultural brasileiro, incorporando novas formas de apreender, viver, explicar e organizar a vida social.

de atuação são consagradas" (KASZNAR \& GRAÇA FILHO, 2002, p. V). Diga-se, de passagem, que as velhas práticas acima mencionadas correspondem, exatamente, à participação do esporte na formação educacional.

16 Há aqui de se observar que a confusão anteriormente citada, referente à responsabilidade pelas políticas de lazer variarem de acordo com o Estado e Município, muitas vezes, pode ser justificada pela tradição e especificidade regional e local. Num Estado, por exemplo, como o Acre, onde o desenvolvimento do lazer está intimamente ligado à questão ambiental, uma "política de lazerania" deve estar diretamente articulada a uma "política de florestania", o que justifica uma composição setorial que leve à criac̃a de uma "Secretaria de Meio Ambiente e Lazer" ou sçă "Secetara de Mo Ambiente, Tuismo de uma "Secretaria de Meio Ambiente, Turismo e Lazer", neste segundo caso, se desenvolvimento do lazer for estimulado pelo viés do ecoturismo. Já num município como Tiradentes-MG, um outro exemplo, onde predomina a tradição de práticas de lazer predominantemente artísticas e culturais, a composição pode se outra, demandando talvez uma "Secretaria de Cultura e Lazer". De qualquer modo, no quadro mais geral, no conjunto maior dos Estados e Municípios brasileiros, ainda pensamos ser apropriado por a centralidade das políticas sociais de lazer no a potencial educativo e enorme capacidade de mobilização que tal fenômeno desperta.

Movimento, Porto Alegre, v. 11, n. 3, p. 155-182, setembro/dezembro de 2005 
Para a efetivação de uma política que, além de reafirmar a responsabilidade do Estado quanto à universalização do direito ao lazer, apóie-se em uma compreensão intersetorial de gestão, minimizando problemas como pulverização e sobreposição de ações, a proposição de um fórum nacional sintonizado com conselhos populares instituídos em todos os níveis de governo - federal, estaduais e municipais -, caracterizando-se como órgãos colegiados, de caráter consultivo, normativo, deliberativo e fiscalizadores, representativos das comunidades esportivas e de lazer, constitui-se, então, como mais uma grande tarefa. Apontamos, deste modo, para a possibilidade de um Sistema Nacional de Esporte e Lazer concebido como expressão institucional do esforço organizado, autônomo e permanente da sociedade civil organizada, primando sempre pela integração das políticas para o setor e diversidade nas ações de governo, balizando-se por princípios como a ética, a democracia e a participação, sem descuidar de sua eficiência e da necessidade de ampliação quantitativa dos espaços e equipamentos para a fruição social do lazer, mas voltando atenção, principalmente, para a qualidade e conquista de uma cidadania socialmente organizada.

E, por fim, não podemos esquecer que nem tudo no Brasil são políticas neoliberais. Temos que prestar mais atenção nas políticas que, de algum modo, explicitam um projeto contra-hegemônico, afirmando a cidadania e o desenvolvimento humano. Referimo-nos às experiências democrático-populares de administração pública principalmente, aquelas desenvolvidas na esfera municipal - que já põem em exercício políticas verdadeiramente transformadoras e emancipatórias, contudo, muitas vezes sem avançar ainda no entendimento e construção de proposições mais críticas o campo específico de intervenção no âmbito do lazer. Isto sem falar da devida pesquisa e análise que merecem as práticas de lazer espontâneas verdadeiramente solidárias e, muitas vezes, até explosivas que brotam no cenário das periferias de nossas grandes e médias cidades, com toda sua tensão, tecendo vínculos entre trabalho, exclusão, inclusão e educação.

\section{Por uma pedagogia crítica do lazer}

Uma "política de lazerania", para que realmente possa se fazer efetiva, necessita de uma estratégia pedagógica que lhe corresponda. Dizemos isso, pois muitas vezes o lazer é compreendido a partir de uma visão espontaneísta, ${ }^{17}$ o que, via de regra, nutri a recusa ante

17 A visão espontaneísta do lazer pode se traduzir por distintos enfoques, dentre os quais destacamos: o enfoque subjetivista, por conceber o lazer como vivência de

Movimento, Porto Alegre, v. 11, n. 3, p. 155-182, setembro/dezembro de 2005 
uma ação sistemática e teleológica no campo. Há de se advertir, no entanto, que qualquer prática educativa, inclusive no âmbito do lazer, além de expressar uma determinada compreensão de mundo, de homem e de sociedade, está submetida a relações hegemônico-pedagógicas que implicam em tensões, disputas e conflitos de interesse. Nesse sentido, a fim de materializar uma intencionalidade ético-política balizada pelos princípios da planificação, da participação, da autonomia, da liberdade, da justiça, da democracia, do bem estar etc., na ponta da intervenção, onde o lazer de fato acontece, também é preciso organização. Sem o auxílio de uma pedagogia com viés crítico, transformador e emancipatório, não há, portanto, possibilidades de que uma "política de lazerania" possa de fato vir a vingar.

Acontece que se buscarmos no campo do lazer referências para a construção de tal proposta pedagógica, o que há indicado como subsídio mais atual para a implementação de políticas de lazer é a estratégia da animação sociocultural. Muito difundida no Brasil a partir de instituições como o SESI e o SESC a partir da década de 1970 e, posteriormente, dos anos 1990 em diante, assimilada e incorporada às políticas públicas de lazer de alguns municípios, tal proposta parece ter se desdobrado em pelo menos duas tendências, uma conservadora e outra reformista. De um lado, a animação se caracteriza como base operacional de funcionalização sistêmica do lazer para o desenvolvimento de setores de vida pelo princípio da auto-ajuda, e, de outro, apresenta-se como estratégia para garantir a difusão dos bens simbólicos historicamente instituídos sob a ótica da difusão cultural. ${ }^{18}$ Afora este par, para Melo e Alves Junior (2003), existiria ainda uma terceira perspectiva. Apoiados em classificação construída por Bernet (1997), sugerem a existência de uma animação dialética, esta sim, verdadeiramente preocupada com transformações estruturais.

O paradigma dialético entende a animação como construção de uma democracia cultural. O animador considera a realidade como base no contexto em que ela se apresenta, tentando interpretá-la de forma global, complexa,

um estado subjetivo de liberdade e expressão da personalidade; o individualista, po considerar que o lazer pertence somente à esfera do indivíduo, independente da coletividade social; e o liberal, por ver no lazer um tema privado o qual a sociedade não pode determinar seu emprego pessoal (MUNNÉ, 1980).

18 Embora estas duas tendências sejam apresentadas aqui em separado, cada qual portando características que Ihes são próprias, há de se dizer que elas não necessariamente se excluem. Elementos de uma e de outra podem aparecer sincretizados numa só proposta ou política de lazer.

Movimento, Porto Alegre, v. 11, n. 3, p. 155-182, setembro/dezembro de 2005 
dialética e diacrônica. Identificando a realidade como historicamente construída, está preocupado com que o conhecimento também seja socialmente situado, sempre em busca de despertar novas consciências. [...] A partir daí, espera-se gerar uma ação transformadora e emancipadora. (MELO \& ALVES JÚNIOR, 2003, p. 63).

Ocorre que se tal formulação sinaliza uma ação crítica e transformadora, falta-lhe, contudo, base empírica de referência na realidade brasileira. ${ }^{19}$ Olhando para as experiências que vêm servindo de parâmetro para as várias iniciativas no campo da animação sociocultural em nosso país, dentre as quais merecem destaque aquelas sistematizadas por Requixa (1973) e Marcellino (1994, 1996), ${ }^{20}$ constata-se a influência do modelo de desenvolvimento comunitário que, conforme chama atenção Brandão (1984, p. 38), com um tipo de ação politicamente esvaziada, é incapaz de promover "mais que efeitos epidérmicos de melhorias das condições de vida no interior de estruturas inalteradas de exploração do trabalho e expropriação do poder do povo". Quando muito criticam o formato de atividades previamente organizadas e defendem a educação e o desenvolvimento cultural a partir da tomada de decisões consciente ante aos conhecimentos, normas e valores transmitidos pelos meios de comunicação de massa.

Diante disso, temos defendido que a ressiginificação das práticas educativas no campo do lazer deve comportar o diálogo com outras referências. O que estamos querendo dizer é que se é mesmo possível uma "animação de novo tipo", dialética e transformadora, o nosso ponto de partida deve se outro. Há de se partir daquilo que há de mais desenvolvido no Brasil como concepção pedagógica progressista no âmbito da educação não-formal para podermos avançar com uma "pedagogia crítica do lazer". E tal concepção, em nossa análise, está colocada pelo legado das formulações freirianas que se vão acompanhando de várias outras e que convencionalmente cha-

19 Destaca-se que a própria apresentação do suposto paradigma dialético de animação, construída por Melo e Alves Junior (2003), apesar de trazer contribuições importantes para pensarmos nas possibilidades da experiência estética no âmbito do lazer, não aparece articulada a nenhuma sistematização propositiva, nem mesmo a uma discussão pedagógica.

20 Muito embora se perceba em N. Marcellino uma postura que o distancia das chamadas abordagens funcionalistas de lazer que se expressam pela ação comunitária, defendendo o lazer como um dos campos possíveis de contra-hegemonia (MAR-
CELLINO, 1987) e desenvolvendo uma concepção educativa baseada no compoCELLINO, 1987) e desenvolvendo uma concepção educativa baseada no compo-
nente lúdico do lazer, denominando-a pedagogia da animação (MARCELLINO, 1997), nos escritos mencionados (MARCELLINO, 1994; 1996), acaba se reaproximando de Requixa (1973), não conseguindo traduzir para sua proposta de animação sóciocultural tal concepção e elementos de crítica.

Movimento, Porto Alegre, v. 11, n. 3, p. 155-182, setembro/dezembro de 2005 
mam educação popular. ${ }^{21}$ Inspirados, portanto, pelos pressupostos teórico-metodológicos sistematizados no campo da educação popular, podemos operar com a idéia de um "lazer problematizador", reclamando o ambiente, a disponibilidade e as condições para que a reflexão elaborada e gerada a partir da vivência da cultura lúdica busque assegurar às classes populares a apropriação de um saber correspondente às suas experiências e reais necessidades, possibilitando-lhes o desenvolvimento de habilidades e valores necessários à sua autodeterminação como sujeito coletivo.

Esta pedagogia privilegia o conhecimento que emerge da própria experiência de vida das classes populares e que é inventado por elas mesmas, reforçando seu poder de transformar a realidade. Esse conhecimento que consta de seu universo lúdico deve ser tratado pedagogicamente a fim de articular macro e micro-relações no sentido de alargar sua capacidade de decidir sobre as estratégias, lutas e formas mais apropriadas para o estabelecimento de novas regras sociais. Seguindo essa premissa, a "pedagogia crítica do lazer" materializa uma prática educativa que visa robustecer a resistência e a luta das classes populares alimentando-se de suas próprias experiências e tradições. Inscreve-se dentro de uma dinâmica cultural já existente como pedagogia que se propõe contribuir para que elas possam desenvolver - ou seja, expressar, valorizar, criticar, enriquecer, reformular, etc. - coletivamente suas formas de aprender e explicar a vida social, buscando valorizar as práticas e valores emancipatórios que brotam de sua cotidianidade.

Assumir tal perspectiva significa ver o processo de organização da cultura lúdica também como um terreno marcado por lutas simbólicas e concretas, o que coloca para os programas e projetos de lazer a necessidade de uma postura orgânica às classes populares, visando aglutinar os movimentos sintonizados com o projeto de qualificação da condição de existência humana - e que podem ser distintos movimentos de negros, movimentos ecológicos, movimentos homossexuais, movimentos da juventude, movimentos feministas, movimentos comunitários, movimentos religiosos, etc. - em torno da luta do trabalho contra o capital, buscando conferir-lhes mais vitalidade e força libertadora. Nessa direção, a intervenção pedagógica do lazer deve ultrapassar os limites da ação cultural

21 Muito embora as bases para a concepção de educação popular de P. Freire possam ser encontradas ao longo de toda sua obra, o debate metodológico que confere sustentação a tal concepção tem maior visibilidade em suas publicações iniciais. Ver Freire $(1980,1983 a, 1983 b)$.

Movimento, Porto Alegre, v. 11, n. 3, p. 155-182, setembro/dezembro de 2005 
devendo se articular à realidade socioeconômica, visando a superação das atuais condições materiais de existência a que estão submetidas às classes populares.

Espera-se, assim, que os sujeitos envolvidos em tal proposta reconheçam-na como tempo e espaço de resistência e organização política, tanto em relação às possibilidades de ocupação e vivência do lazer como em relação ao encaminhamento de estratégias de mudança, tanto no que toca à necessidade de democratização do acesso à fruição dos bens culturais como no que se refere à participação na produção, reprodução, sistematização e difusão da cultura, nas decisões políticas e na condução da vida social. Para tanto, a fim de que se criem as condições para a democracia participativa, é preciso romper com a base operacional piramidal sobre a qual tradicionalmente se estruturam as propostas e programas de lazer, com animadores de competência geral gerenciando pelo alto suas ações, animadores de competência específica supervisionando-as mais de perto e animadores voluntários de base fazendo a ligação na ponta do trabalho. Uma "pedagogia crítica do lazer" requer a organização coletiva do trabalho pedagógico, sem abdicar da divisão de atribuições e responsabilidades, mas compreendendo que todas pessoas engajadas no trabalho com o lazer, ${ }^{22}$ como educador coletivo, e também o grupo envolvido na própria vivência do lazer, estão ligados mutuamente por relações e dependências diretas.

Ao buscar a construção de um método que subsidie a abordagem de programas e projetos de lazer, temos de optar por uma estratégia que pressuponha a superação de antigos modelos de intervenção pedagógica assentados no espírito de desenvolvimento comunitário. Uma política de lazer sintonizada com interesses democrático-populares deve pautar-se pela construção e valorização de propostas teórico-metodológicas que problematizam as contradições e condições concretas de vida do grupo com que se trabalha, vendo no lazer mais um instrumento de empoderamento das classes populares, o que constitui alternativa para a recriação e superação das atuais propostas de lazer. ${ }^{23}$ Para fazermos do lazer um tem-

22 Vale dizer que o trabalho com o lazer na perspectiva em questão lida, necessariamente, com o envolvimento de grupos, e requer, sim, o engajamento voluntário em maior ou menor escala de indivíduos e coletividades. No entanto, isto não pode justificar a dispensa da figura do educador profissional atuando com diretividade e presença permanente em todo processo de trabalho, principalmente na ponta da intervenção.

23 Vale aí localizar experiências que possam nos deixar ensinamentos para tal construção. Em trabalho anterior, a partir de uma experiência específica de intervenção, pudemos sistematizar algumas indicações propositivas de caráter teórico-metodológico

Movimento, Porto Alegre, v. 11, n. 3, p. 155-182, setembro/dezembro de 2005 
po e espaço voltado para o exercício da cidadania e da participação social, é fundamental que avancemos neste ponto, com a proposição e sistematização de metodologias que tenham na dinâmica da realidade econômica, política e cultural seu critério de verdade, identificando desafios, antecipando possibilidades e abrindo caminho para uma conquista deveras incompleta, a "lazerania".

\begin{abstract}
Leisure and utopia:
Limits and possibilities of politic action

Abstract: This text presents a purpose synthesis in direction to the renew of leisure politics. Built on a dialectical conception of history, is based on the critical balance of the changes that made leisure, during the last decades, the symbol of market, as far as the analysis of contradictions related to this process on its alternative possibilities. Defends concrete proposals, making program of appointments to a public leisure politic, further more asks for a pedagogical strategy that, in the daily action of such politics, can increase, together with the civilian society, another type of sociability and fun experience, articulated to the utopia of a new way to conceive and organize life itself.

Keywords: Leisure, Education, Social Politics.
\end{abstract}

\title{
Ocio y utopía: \\ Límites y possibilidades de ación política
}

Resumen: Este texto presenta una síntesis propositiva en la dirección de la renovación de las políticas del ocio. Anclado en una concepción dialética de la historia, fufamenta en el balancear crítico de las transformaciones que fueram impuestas al ocio, a lo largo de las dos décadas, la marca de la mercancía, bien como em el examen de las contradiciones esenciales neste proceso en sus posibilidades superadoras. Sustenta propuestas concretas, fijando apuntamientos programaticos para una política pública del ocio, para más allá reivindicar una

na direcão de uma "pedagogia crítica do lazer". Ver Mascarenhas (2003). Já no âmbito de políticas de lazer implementadas em âmbito municipal que dialogam com a concepção freireana de educação popular, contribuições significativas podem ser localizadas em Santos, Moreira e Sousa (2002) e Silva e Silva (2004), referentes, respectivamente, à experiência democrático-popular de gestão das cidades de Belém-PA, 1997-2004, e de Recife-PE, 2001-2004.

Movimento, Porto Alegre, v. 11, n. 3, p. 155-182, setembro/dezembro de 2005 
estrategia pedagogica que, en la ación cotidiana de estas políticas, puedan potenciar junto a la sociedad civil, un otro tipo de sociabilidad y experiencia ludica, articulada a la utopía de un nuevo modo de se concebir y organizar la vida.

Palabras-clave: Ocio, Educación, Políticas Sociales.

\section{Referências}

AMARAL, Silva Cristina Franco. Políticas públicas de lazer: existe possibilidade de uma gestão participativa? Campinas: fotocopiado, 2004.

ANTUNES, Ricardo. Os sentidos do trabalho: ensaio sobre a afirmação e a negação do trabalho. São Paulo: Boitempo, 1999.

BENSAID, Daniel. Marx, o intempestivo: grandezas e misérias de uma aventura crítica (séculos XIX e XX). Rio de Janeiro: Civilização Brasileira, 1999.

BERNET, Jaume Trilla. Animación sociocultural: teorías, programas y ámbitos. Barcelona: Ariel, 1997.

BRANDÃO, Carlos Rodrigues. Da educação fundamental ao fundamental na educação. In: Pensar a prática: escritos de viagem e estudos sobre a educação. São Paulo: Loyola, 1984. p. 13-62.

CASTELLANI FILHO, Lino. Política educacional e educação física. Campinas: Autores Associados, 1998.

FREIRE, Paulo. Conscientização: teoria e prática da libertação. 3. ed. São Paulo: Moraes, 1980. $\overline{1983}$.

Educação como prática da liberdade. 14. ed. Rio de Janeiro: Paz e Terra,

_. Pedagogia do oprimido. 13. ed. Rio de Janeiro: Paz e Terra, 1983.

GRAMSCI, Antonio. Maquiavel, a política e o Estado moderno. 2. ed. Rio de Janeiro: Civilização Brasileira, 1976.

HOBSBAWM, Eric. A era dos impérios: 1875-1914. 3 ed. Rio de Janeiro: Paz e Terra, 1992.

KASZNAR, István; GRAÇA FILHO, Ary. O esporte como indústria: solução para criação de riqueza e emprego. Rio de Janeiro: CBV, 2002.

MARCELLINO, Nelson Carvalho. Lazer e educação. Campinas: Papirus, 1987.

Movimento, Porto Alegre, v. 11, n. 3, p. 155-182, setembro/dezembro de 2005 
MARCELLINO, Nelson Carvalho. Capacitação de animadores sócio-culturais Campinas: Unicamp; Brasília: Ministério da Educação e do Desporto, 1994.

Pressupostos de ação comunitária - estruturas e canais de participação. In: . (Org.). Políticas públicas setoriais de lazer: o papel das prefeituras. Campinas: Autores Associados, 1996. p. 39-42.

_... Pedagogia da animação. Campinas: Papirus, 1997.

MASCARENHAS, Ângela Cristina Belém. O trabalho e a identidade política da classe trabalhadora. Goiânia: Alternativa, 2002.

MASCARENHAS, Fernando. Lazer como prática da liberdade: uma proposta educativa para a juventude. Goiânia: Ed. UFG, 2003.

"Lazerania" também é conquista: tendências e desafios na era do mercado. Movimento, Porto Alegre, v. 10, n. 2, p. 73-90, mai./ago. 2004.

Entre o ócio e o negócio: teses acerca da anatomia do lazer. Tese (Doutorado em Educação Física) - Faculdade de Educação Física, Universidade Estadual de Campinas, Campinas, 2005.

MELO, Victor Andrade de; ALVES JUNIOR, Edmundo de Drummond. Introdução ao lazer. Barueri: Manole, 2003.

MÉSZÁROS, István. Para além do capital. Rumo a uma teoria da transição. Campinas: Unicamp; São Paulo: Boitempo, 2002.

Economia, política e tempo disponível: para além do capital. Margem es querda: ensaios marxistas, São Paulo, n. 1, p. 93-124, mai. 2003.

MUNNÉ, Frederic. Psicosociología del tiempo libre: un enfoque crítico. México: Trillas, 1980

NOGUEIRA, Marco Aurélio. As três idéias de sociedade civil, o Estado e a politização. In: COUTINHO, C. N.; TEIXEIRA, A. P. (Orgs.). Ler Gramsci, entender a realidade. Rio de Janeiro: Civilização Brasileira, 2003. p. 215-233.

POCHMANN, Marcio. e-trabalho. São Paulo: Publisher Brasil, 2002.

PORTELLI, Hugues. Gramsci e o bloco histórico. 5. ed. Rio de Janeiro: Paz e Terra, 1990.

REQUIXA, Renato. Lazer e ação comunitária. São Paulo: SESC, 1973.

RIEDE, Antonio Sérgio; BRAMANTE, Antonio Carlos. Realinhamento dos fatores críticos de sucesso na gestão de clubes social-recreativos baseado no conhecimento dos sistemas internos e externos: o caso das AABB's. Licere, Belo Horizonte, v. 6, n. 1, p. 29-45, set. 2003.

SANT'ANNA, Denise Bernuzzi. O prazer justificado: história e lazer (São Paulo, 1969/1979). São Paulo: Marco Zero; Brasília: MCT-CNPq, 1994.

SANT'ANNA, Denise Bernuzzi. Corpos de passagem: ensaios sobre a subjetividade contemporânea. São Paulo: Estação Liberdade, 2001.

Movimento, Porto Alegre, v. 11, n. 3, p. 155-182, setembro/dezembro de 2005 
SANTOS, Dalva; MOREIRA, Fátima; SOUSA, Roseli. (Orgs.). Esporte, arte e lazer em Belém - sob o olhar dos que fazem. Belém: SEMEC; Graphitte Editores, 2002.

SILVA, Jamerson Antonio de Almeida da; SILVA, Katharine Ninive Pinto. Círculos populares de esporte e lazer: fundamentos da educação para o tempo livre. Recife: Bagaço, 2004.

SNYDERS, Georges. A alegria na escola. São Paulo: Manole, 1988.

Recebido em: 31.08 .05

Aprovado em: 27.09 .05

* Professor da Universidade Federal de Goiânia.

Movimento, Porto Alegre, v. 11, n. 3, p. 155-182, setembro/dezembro de 2005 